\title{
Promoting Bangladesh Tourism through the Internet: Theoretical Perspectives and Empirical Evidence
}

\author{
Md. Afjal Hossain ${ }^{1 *}$, Jameni Jabed Suchana ${ }^{1}$, and Md. Ashikur Rahman Avi ${ }^{2}$ \\ ${ }^{1}$ Department of Tourism and Hospitality Management, University of Dhaka, Dhaka, Bangladesh; and ${ }^{2}$ Department of \\ Tourism and Hospitality Management, Pabna University of Science and Technology, Pabna, Bangladesh. \\ *Correspondence: afjaldu@hotmail.com (Professor, Md. Afjal Hossain, Department of Tourism and Hospitality \\ Management, University of Dhaka, Dhaka, Bangladesh).
}

\begin{abstract}
This study explores how the Internet helps promote tourism in Bangladesh. It has presented the applicability of the Internet in the promotional activities of the tourism industry in Bangladesh and also studied the present status of the usages of the Internet in its tourism promotional activities of the same. The advantages of Internet promotion in the contemporary tourism industry are also analyzed here in brief. Internet can spread essential information about tourism destinations rapidly and their services at a lower cost. Internet also helps build awareness, increase destination loyalty, allow flexibility of messages, ensure speedy information transfer and retrieval, and improve interactive relationships. The study also highlighted the limitations affecting the expansion of Internet usages in the tourism industry in Bangladesh. The paper concluded with some policy and strategic guidelines about how to develop Internet promotion for the tourism industry in Bangladesh.
\end{abstract}

Keywords: Bangladesh, Tourism, Industry, Empirical Evidence, Internet, Theoretical perspectives, and Promotion.

\section{INTRODUCTION:}

The concept "Internet" means 'a global network of networks among the interlinked computers that operate on a standard protocol allowing transfer of data between them' (Liu, 2000). It is an interactive and universal means of communication creating easy access to users worldwide. Millions of computer-users can share necessary information like numbers, texts, sounds and images (Young, 1999). It connects companies with customers and people with people regardless of time, space and platforms (Mathur et al., 1998). Internet helps process, analyze, present, store and disseminate information of the tourism industry in a labour-efficient and cost-effective way (Liu, 2000). Tourists can use it for booking of hotel rooms, package tours, air tickets and other services almost instantaneously (Wen-Hsiang, 2013). Thus, Internet is a popular medium for tourism promotion. It has replaced the traditional promotional approaches of the tourism industry and proved to be an effective means to attract more visitors (Ma et al., 2003; Sardar et al., 2020). As such, many tourism firms of the destination countries have been utilizing the Internet successfully for their marketing and promotional activities. As tourists depend much on the information before making a travel decision, they try to find out an easy and authentic source of information in making the right choice of destination. Internet is the easiest way of getting such information. As such, they are also utilizing the Internet information for their decision 
making on destination choice and planning their trip (Slevin, 2006). In Bangladesh, Internet-based marketing and promotional activities can be the most ideal and popular procedure for delivering goods and services, promoting customers and transferring digital information (Rahman and Rahman, 2020). In spite of having huge potentials of tourism, Bangladesh lacks in effective promotional activities due to fund crisis. Today, Internet has come up to address this problem and tourism firms in Bangladesh can now promote their activities and services in a cost-effective way.

\section{Literature Review}

Internet plays a vital role in promoting goods and services. As tourism industry consists of many small firms having little ability to promote their services using mass and selective media, internet helps them solve this problem and promote their services at minimum cost. Bangladesh tourism industry is of no exception from this. Some worldwide works on the Internet-based Tourism Promotion (ITP) have been found by the authors. But no work on the Internetbased tourism promotion in Bangladesh has yet been available (ALsarayreh et al., 2011). As such, by reviewing the available papers, the researchers have developed the framework of the present research work. The important ones reviewed here are as under:

Moutinho (1987), found that tourists depend much on the information before making a travel decision. Buhalis (1998) indicated that tourism firms utilized successfully the Internet and Extranet in providing tourists with pre-trip and in-trip information; helping tourism firms promote their products. Tourism industry can gain important synergies by using the Internet. Lai and Vinh (2012), showed that Internet has a positive impact on destination expectations. Poon (1993), Hanna (1997), noted that Internet has become critical on the survival of companies in the economy. According to Liu (2000), the Internet is an ideal tool for tourism promotion and it has profoundly changed the way of conducting tourism business. Benckendorff and Black (2000) claimed that the Internet's rich proliferation of text and multimedia provide a range of stimuli to encourage people to buy travel products. To Garin-Munoz and Perez-Amaral (2010), travel products are suitable for online selling, as these have characteristics and suitability to electronic environment. Al-Kassem and Nassuora (2012), described the Internet as an important source of information for travel related decision making. To them, it helps booking air tickets, hotels, and other tourism supplies, and making payments through credit card. Batinic (2013), presented the pros and cons of the Internet used in contemporary travel agencies and tour operators. To him, the Internet technology provides high-quality and efficient operations of a service industry like tourism. As such, tourism firms must use the Internet effectively to create new competitive advantages.

Research Gap: There are some studies worldwide on the Internet-based tourism promotion. But there is no study in Bangladesh in this area. As such, the present study on 'promoting Bangladesh tourism through the Internet' deserves an utmost attention for the present day tourism industry in Bangladesh. Bangladesh has huge potentials to develop its tourism and, hence, it requires useful promotional activities to develop this industry. As such, an attempt to explore the role of Internet-based promotion of Bangladesh tourism is felt needed by the authors.

Rationale of the Study: As mentioned, there is no comprehensive study on the Internet-based tourism promotion in Bangladesh. As such, the present study will help in filling the gap of current knowledge on the Internet-based tourism promotion in Bangladesh. This study will also help conceptualize future researchers to undertake further intensive and conclusive research on how the Internet will help promote Bangladesh tourism in a cost-effective way in comparison to other forms of traditional promotion.

An assessment of the factors that influence the performance of the Internet-based tourism promotion and that need to be considered while promoting tourism through the Internet by the tourism industry in Bangladesh can also be made on the basis of the present study. The findings, limitations and recommendations accommodated in this study are expected to help the policy-planners of Bangladesh tourism industry to making strategic and effective decisions in this regard. 


\section{Objectives of the study}

The main objectives of this research paper are to focus on the importance of the Internet-based tourism promotion (ITP), explore the nature and extent of the usages of Internet by Bangladesh tourism industry, and to set guidelines for effective Internet-based promotion of Bangladesh Tourism. The specific objectives of the study are:

1. To focus on the importance of Internet as a tool for tourism promotion;

2. To study the nature and extent of Internet usages by Bangladeshi tourism firms to promote Bangladesh destinations and their products and services;

3. To identify the challenges faced by Bangladeshi tourism firms in the usages of Internet promotion; and

4. To suggest Internet-based promotion strategy for the industry in Bangladesh.

\section{METHODOLOGY:}

The study could not collect enough secondary materials in this area of Bangladesh, as there is a lack of study in Bangladesh and hence there is very little by the way of literatures. Since the present research on 'Promoting Bangladesh Tourism through the Internet' is not available, this research can be called an exploratory work. As this paper attempts to provide an insight into how the Internet can help promote Bangladesh tourism to the potential tourists of home and abroad, it is also a conceptual research work. As an exploratory and a conceptual research work, a qualitative approach was adopted to identify and recognize the issues relevant with the promotion of Bangladesh tourism by using Internet.

The study used a semi-structured questionnaire for 10 hotels and another set of same type of questionnaire for 10 tour operating firms in Bangladesh to collect indepth information in connection with the usages of Internet for their promotional activities. Another set of semi-structured questionnaire was distributed among 100 visiting tourists in Cox's Bazar (50), Kuakata (30) and Bandarban (20). Subsequently, the collected information was analyzed systematically by using simple statistics like percentage, frequency, mean, standard deviation, etc. As such, the nature of this research is a combination of both conceptual and qualitative ones, and the researchers could not draw any precise hypothesis regarding this research work.

\section{ANALYSIS AND FINDINGS:}

Bangladesh is a land of scenic beauty. There is a saying that "Bangla has hundred gates open for entrance, but not a single one for departure (Hossain, 2010)". She has six seasons with unique charms in each season, world's largest mangrove forestSundarban, and world's longest unbroken sea beachCox's Bazar, diversified culture and festivals, hospitable people, three world heritage sites declared by the UNSCO, famous religious and archeological sites, delicious foods, amazing hill tracts areas, incredible natural beauties and so on. These need to be promoted effectively and make these attractive to the tourists. But the country has failed to attract enough foreign tourists to visit the country. Many reasons might be there for such a failure to attract tourists. But the main reason, as indicated by the sample respondents, is lack of promotional activities by the industry and the government of the country. Anyway, the Internet can solve the promotional problems of the industry, if used properly and effectively. The key findings of this study are presented and discussed as under:

A. Traditional tourism promotional tools vs. the internet promotion: The internet is a multidimensional medium, in contrast to other traditional media like radio, television, brochures, magazines, etc that target only one dimension (Al-Kassem and Nassuora, 2012). Basically, the Internet was used as a communication channel and as a part of direct marketing (Alfa and Varfan, 2006). The usages and the importance of Internet for tourism industry have changed fast over the last few years (Garin-Munoz and Perez-Amaral, 2010). Initially the Internet was used for e-mailing and getting response from customers. "Today, the Internet can be used for brand name recognition, direct sales, advertising, customer supports and assistances (Liu, 2000). It also functions as an information source, a means of comparing competitors, and a channel of booking or purchasing travel products (Al-Kassem and Nassuora, 2012). 
The information can be stored, retrieved, and restructured automatically without human intervention (Liu, 2000; Amin, 2020). As such, the Internet has been a common media for presenting the services, an effective marketing tool, and an image building agent of the company. It has been found to have huge impacts on tourist markets. The growth can be seen as on a technical level, costs of using internet and accessibility of it to tourist markets. Today $3,73,19,73,423$ peoples all over the world use Internet (http://www.internet worldstats.com/stats.htm, March 31, 2017). Thus, the Internet has been an accessible and popular promotional tool. Traditional media as promotional tools can reach few potential tourists. But now the Internet has changed this trend dramatically. People now are watching more on online in their computers using internet, smart phones and other multimedia devices. A new in-depth report from tracking firm Nielsen shows that individuals are spending more hours surfing web and viewing streaming services (http://www.digitalcommons.unl.e du/zeabook/33/).

By using Internet, marketer can easily make senses on the comments, reactions and feedback about their offers. Tourism promoters are now more interested to use Internet promotion because its cost is very low. In a changed situation, tourism marketing firms are now able to respond instantly due to interactive facilities. It gives huge advantages to business owners to understand the current tastes and expectations of tourists. Print media hold informative and entertaining contents and provide many targeting option but none for tracking effectiveness. Tourism firms may measure the sales volume of the magazine but they fail to track how many people have viewed the advertisement and thus fail to measure the effectiveness of the advertisement. The print media are not reliable and interactive. But Internet, as a social media, provides reliable and interactive information to the potential tourists. Billboards are innovative media viewable by everyone on the road. But there is no option to track and measure the results and the effectiveness of advertisement. On the contrary, marketer now can use email marketing by which they can track their effectiveness by calculating the number of tourists' responses.

UniversePG I www.universepg.com
It is easier for tourism firms to stay in touch with tourists 24/7 through the internet. Marketers can track the number of viewers from the user cookies. But this is not possible in one way communication. Potential tourists can view the marketing catalog for specific tourists' products, tour packages, and hotel services on the internet according to their choices. As an interactive media, tourists can also find answers to their requests via online chat by posting their questions.

B. Role of the internet in tourism promotion: The Internet can play various roles within the tourism industry as a communicative tool and as an information source (Al-Kassem and Nassuora, 2012). The following are the roles which internet can play in the promotional activities of destinations in general and in Bangladesh in particular: The Internet creates accessibility and connectivity throughout the world. The rich text of the Internet helps tourists to buy travel products (Benckendorff and Black, 2000). Using Internet, tourists can select destinations, forward orders, buy airline tickets and make payments through electronic process.

Similarly, tourism firms can sample their tour packages; illustrate pictures of destinations and hotel rooms; send booking-conformation notices and invoices; and can provide other services. Internet is a device for global distribution system called emediaries. The web-based travel reservation systems are much easier and convenient (Liu, 2000). It gives the possibility to purchase travel products on-line just as easily (Buhalis and Licata, 2002). Internet helps create direct networks and open avenues between tourism suppliers and tourists crossing borders, which was impossible in the past without intermediaries.

Offering direct links between the producer and the consumer, the Net helps the producer save huge distribution costs through the disintermediation process (Liu, 2000; Shili, 1998). Consumers can interact directly with service suppliers, which allows service providers to know and satisfy customers' changed needs of tourism products (Mills and Law, 2004; Gursoy and McCleary, 2004). Similarly, tourism suppliers also may deal with tourists more effectively in the increasing complexity and diversity 
of their needs (Garin-Munoz and Perez-Amaral, 2010).

It enables tourists to communicate with tourism firms on 24 hours a day and 365 days a year basis (Buhalis and Licata, 2002). The Internet is so special with regard to high-speed information transmission and retrieval (Liu, 2000). Internet marketers can do what a sales-force can do but with much more flexibility and less cost (Kiani, 1998). The Internet is a low cost promotional media. Tourism firms can sample their products/services on the Web to promote these electronically and economically to remote and insular destinations. It enables tourism firms to reduce their promotional costs and thus increase their profitability. The Internet can reach promotional messages on oneto-one and one-to-many basis. Each time a user visits its web site; its server creates a record of the user's electronic address (Liu, 2000). The company can then "narrowcast" - send tailor-made message content- to a smaller target audience or an Individual consumer (Heinen, 1996; Hoffman and Novak, 1996). Thus, the Internet represents the opportunity to customize and tailor the product and/or the marketing effort to one customer at a time (Liu, 2000).

Tourists' satisfaction depends highly on the accuracy of information on destinations' accessibility, facilities, attractions and activities (Buhalis, 1998). Tourism firms may embed photographs along with necessary information. Potential tourists can compare and evaluate those pictures, destinations and hotel rooms before they go there. This definitely will help encourage them to make a positive travel decision in Bangladesh. "The Web is a much more flexible medium than the traditional media. The websites can always change messages, which are immediately visible and are not limited to space and time (Raza, 2006).

Besides, in case of any change in demand, supply, competition or price, tourism firms have to take long time to make necessary corrections and send supplements to the brochures or folders printed earlier. But in the case of Internet, tourism firms can make those necessary adjustments or changes instantly on the Web. Thus, internet promotion ensures information speed, reduces dissemination costs, improves UniversePG I www.universepg.com reliability, and ensures direct interaction. The Internet also ensures user-friendly interaction among participants and builds closer relationship between clients and suppliers. As such, it is expected that internet based promotion will dominate our tourism's firms' promotional activities in the near future due to the reasons mentioned above. For this, the firms of the tourism industry must come up with their promotional activities to implement through the Internet.

\section{Usages of the internet by the tourism firms in} Bangladesh: The Internet-based promotional activities of the tourism firms are in its infancy. But the most important factor affecting the choice of destinations and other services is information. The most easily available information source is the Internet. All the respondents of 10 hotels and 10 tour operators agreed that their Internets have been convenient to operate their businesses online. But how far their internets promote their services remains a question. Respondent executives of 7 hotels and 5 tour operators felt that the internet information promotes their services, but not that much effectively. According to the respondent executives of hotel firms, $50 \%$ of their room bookings on an average are made online. According to the tour operator's category of respondent executives, $35 \%$ of their package tours on an average are booked through online.

\section{Limitations of internet-based tourism promotion}

Despite the potential benefits of the internet promotion, it may not work all the time. The full potential of Internet promotion can't be exploited due to following reasons:

\section{i. Internet information is not always reliable:} Information passed through the internet is not always complete and reliable. Sometimes, information available on the internet may be chaotic and misleading due to lack of standardization.

ii. Security level: One common security threat includes the illicit data modification and unauthorized usages of the internet. Gaining access to networks is another concern. Online bill payment is also not always secured. Hackers may come to know the PIN numbers of customers' cards and thus draw money using fictitious cards and the PIN number. Thus, the security of the information, data modification and 
transactions is one of the common concerns (http://www. ukessays.com/).

iii. Direct contact is essential: Some products and services demands direct contact with the providers (Batinic, 2013). Tourism destinations, hotel services, restaurant services and SPA services can't be evaluated based on information and pictures provided in the internet. As such, potential tourists are less likely to form a good impression, which in turn, may not influence the decision making process (http://www.ukessays.com/) on destination and service choices.

iv. Demand of the tourists: The demand of Bangladesh tourism destinations is very low due to political chaos, insecurity of movement and lack of hygienic food and drink. Due to this insufficient demand from tourists, the size of Internet transactions of Bangladesh tourism firms is very small.

v. Lack of uninterrupted internet connection: Lack of uninterrupted internet connection in the country discourages tourism firms to use the Internet and promote their activities to outside world. Rather, they prefer to attract domestic customers through posters, folders, brochures, and newspaper advertisements.

vi. Technological limitations: Internet technology itself imposes constraints to conducting web-based tourism promotion. The poor speed of Web, often called as the 'World Wide Wait", slows down the process of the internet based tourism promotion.

vii. Organizational factor: Internet promotion is not sufficiently undertaken by many of our tourism firms. Besides, many of the tourists are not technologically well-equipped or sound about how to book travel packages by using the Internet.

viii. Administrative issues: The users cannot control on the structure and content provided in the Internet. Governments of Bangladesh is enacting regulations and principles to ease and control its' commercial use and thus helping tourism firms to adopting internetbased promotional activities.

ix. Loosing of competitive edges from the internet promotion: Competitive edge arising out of the Internet promotion by a tourism firms may not sustain for longer period. Competitors may also adopt the same type or IT and Web Sites (O'Brien, 1992). As such, the firms using Internet promotion lose their competitive edges.

x. Internet does not guarantee profitability: The Internet does not guarantee profitability and they may even worsen the compositions of firms and the attractiveness of an industry (Buhalis, 1998). Internet related costs (installation, training, and staff salary) sometimes exceed the benefits to be derived. Though the Internet is a major source of marketing promotion, the websites of Bangladesh tourism have failed to contribute significantly to visitor arrivals here. Bangladesh Tourism Board as the national tourism organization and Bangladesh Parjatan Corporation as the public sector commercial organization have also failed to contribute much to tourist arrivals.

\section{Guidelines and policy implications}

For effective promotional activities, Bangladesh tourism industry should utilize the lower cost internet promotion. The paper recommends the following policy guidelines for effective presentation, promotion and interaction with potential tourists:

1. The industry should develop effective Internet-based promotional programs for disseminating information about its services and facilities to achieve the best benefits.

2. According to the $67 \%$ sample tourist respondents, important information should be accompanied by sufficient photographs and videos to make it more appealing.

3. Tourism firms in Bangladesh should utilize Internet promotion because it helps increase price competition of tourism firms. As such, the paper recommends conducting comparative studies between the tourism promotion via the internet and other means of promotion in terms of cost and efficiency.

4. Search Engine Optimization (SEO) must be ensured to provide the tourists with the basic information at the first sights/page. It is the process of improving the visibility of a website or a web page in search engines via the 'Natural' or 'Unpaid' search result (Glazier, 2011). The 'visit Bangladesh' Website should consider (i) quality contents, (ii) 
optimization of key backend elements (title tags and meta-tags), (iii) branding the site, (iv) fresh contents of destinations, and (v) shareable contents to obtain maximum traffic.

5. The Internet is an important tool in aiding tourists' decision making (Govere et al., 2013). Bangladesh should develop an informative website to ensure good 'encounters' with tourists. A team consisting of experts from marketing, IT, ministry, private operators and tourism experts should under take an initiative in this connection.

6. The Website information given by Bangladesh tourism industry should be downloadable by the users. As such, they will be able, if needed to print information brochures and maps to plan their trips to Bangladesh. As such, tourism firms in Bangladesh using internet promotion should make their brochure available online in PDF (Portable Document File) form.

7. For effective internet-based tourism promotion, the industry should have thorough understanding in information technology, promotional activities and tourism marketing. For this, firms need to train their employees intensively on these areas.

8. Private tourism firms in Bangladesh cannot undertake huge promotional activities due to lack of funds. Public sector tourism firms (BTB and BPC) also face scarcity of funds to come up with necessary budgets and undertake promotional activities for our tourism. Today, the internet has solved this problem, both for private and public sectors. They can undertake promotional activities by using the internet.

\section{CONCLUSION:}

Tourism is an information-intensive service. Internet has proved as the most efficient global medium for information exchange. In modern travel business, the internet has proved to be an effective medium for tourism promotion. The above discussion also highlights that the Internet plays a very important role in the promotional activities of tourism products and services. There are enormous opportunities for all stakeholders in tourism industry to successfully promote and sell their tourism services. Providers can also act in accordance with desires and needs of tourists. Besides, increasing internet speed, lowering internet access costs, tourism firms' commitment to the tourists to deliver superior value, securing privacy of tourists etc. can remove the constraints of internet tourism marketing. Distribution of services depends less on the quantity of printed catalogues and brochures, but information on tourism services can reach millions of internet users. The number of Website browsers has reached to hundreds of thousands. All these justify the exploitation of full potentials of tourism promotion through the internet. But many success factors are absent in the design and operation of the Websites of the tourism firms in Bangladesh. Some tourism firms have their Websites, but these do not contain enough information and hence are not effective. Most of these Websites do not fulfill SEO conditions. Bangladesh tourism firms also face some challenges including poor speed of the Web, absence of Web designers and IT professionals, disruption of power supply in the country, lack of awareness among domestic tourists to book through internet, and lack of interest among foreign visitors to visit Bangladesh. However, the continuous improvement of information technologies will again provide more opportunities for tourism firms to seize the full potentials of the internet tourism promotion at relatively lower costs and with minimum inconvenience. Bangladesh tourism firms cannot afford enough resources to promote their services through brochure, folders, and TV advertisements. As such, internet has opened a low cost and efficient avenue to promote their tourism services and activities. To face global competition, the industry should realize immediately the importance of the internet and start adopting proper strategies to promote the sector through the internet. To become successful in its promotional activities, tourism stakeholders should focus on the internet promotional tools and the SEO. With the changes of the market trend and technologies, Bangladesh tourism firms should update their strategies, technologies and message contents to adapt with the new situations. 


\section{ACKNOWLEDGEMENT:}

The authors acknowledge with respects and gratefulness to those who helped in the process of writing this article. The authors also acknowledge the contributions of those authors of the articles from where references are cited.

\section{CONFLICT OF INTERESTS:}

We, as authors, declare that there will not arise any conflict of interest or any competing interest with any author, firm or other concerned.

\section{REFERENCES:}

1. Alfa, S., and Varfan M., (2006), "The Comparison of Structure Differences between Internet Marketing and Traditional Marketing”. International $J$. of Management and Enterprise Development, 3(4), 397.

2. ALsarayreh, M. N.; Jawabreh, Q. A. A.; ALkharabsheh, K. S.; and Aldahamsheh, M. M. (2011)., "Tourism Promotion through the Internet, (Websites): Jordan as a Case Study", Asian Social Science, 7(6), 125-135. https://doi.org/10.5539/ass.v7n6p125

3. Al-Kassem, A., and Nassuora, A. B., (2012), "The Relationship between Internet Usage and the Marketing of Tourism in Jordan", International Journal of Economics and Management Sciences, 1(7), 75-79. https://www.hilarispublisher.com/abstract/therelationship-between-internet-usage-and-themarketing-of-tourism-in-jordan-19443.html

4. Amin MR. (2020). Human capital investment and its impact on firm's performance: a study on private commercial banks in Bangladesh, Can. J. Bus. Inf. Stud., 2(4), 66-74. https://doi.org/10.34104/cjbis.020.066074

5. Batinic, I., (2013), "The Role and Importance of the Internet in Contemporary Tourism in Travel Agencies Business", International Journal of Cognitive Research in Science, Engineering and Education, 1(2), 1-6.

6. Benckendorff, P. J., and Black, N. L., (2000), "Destination Marketing on the Internet: A Case Study of Australian Regional Tourism Authorities", The Journal of Tourism Studies, 11(1), 11-21.

https://espace.library.uq.edu.au/view/UQ:240532

UniversePG I www.universepg.com
7. Buhalis, D., (1998), "Strategic Use of Information Technologies in Tourism Industry", Tourism Management, 19(5), 409-421. https://doi.org/10.1016/S0261-5177(98)00038-7

8. Buhalis, D., and Licata M. C., (2002), "The Future of e-Tourism Intermediaries", Tourism Management, 23, 207-20.

9. Garin-Munoz, T., and Perez-Amaral, T., (2010), "Internet Usage for Travel and Tourism: The Case of Spain", ECONSTORE: Paper presented on $21^{\text {st }}$ European Regional ITS Conference at Copenhagen, 13-15 September. http://hdl.handle.net/10419/44440

10. Glazier, A., (2011), Searchial Marketing: How Social Media Drives Search Optimization in Web 3.0, February 18, 15. https://www.amazon.com/Searchial-MarketingSocial-Drives-Optimization/dp/1456738925

11. Govere, W. D., Tsokota, T., Chikuta, O., Mukwembi, A., and Chinofunga, P., (2013), "The Use of the Internet to Attract Tourists to Zimbabwe: An Analysis of the Zimbabwe Tourism Authority Website", Intern. J. of Tourism Management \& Business Studies, 3(1), 132-136.

http://ir.msu.ac.zw:8080/jspui/bitstream/11408/4 32/1/tsokota\%20etal.pdf

12. Gursoy, D. and McCleary, K., (2004), "An Integrative Model of Tourism Information Search Behaviour", Annals of Tourism Research, 31(2), 353-373.

13. Hanna, J.R.P., and Millar, R.J., (1997), and Hanna, J., and Millar, R., (1997). "Promoting Tourism on the Internet", Tourism Management, 18(7), 469-470.

14. Heinen, J. (1996), "Internet Marketing Practices", Information Management and Computer Security, 4(5), 7-14. https://doi.org/10.1108/09685229610153120

15. Hoffman, D.L. and Novak, T.P., (1996), "Marketing in Hypermedia Computer-Mediated Environments: Conceptual Foundations", Journal of Marketing, 60(3), 50-68. https://doi.org/10.1177/002224299606000304

16. Hossain, M., (2010), From Protest to Freedom: A Book for the New Generation: the Birth of Bangladesh. 19. Pp277. 
17. Jagboro, K., (Unknown), “A Case Study of Internet Usage in Nigerian Universities: A Case Study of Obafemi Awolowo University, ile-ife Nigeria, 8(2-3). https://doi.org/10.5210/fm.v8i2.1033

18. Kiani, G.R. (1998), "Marketing Opportunities in the Digital World", Internet Res., 8(2), 185194. https://www.deepdyve.com/lp/emerald-pub lishing/marketing-opportunities-in-the-digitalworld-NiIAmNhlhc

19. Lai, Wen-Hsiang and Vinh, N. Q., (2013), "Online Promotion and Its Influence on Destination Awareness and Loyalty in the Tourism Industry", Advances in Management \& Applied Economics, 3(3), 15-30.

http://www.scienpress.com/Upload/AMAE/Vol \%203_3_2.pdf

20. Liu, Z., (2000), "Internet Tourism Marketing: Potentials and Constraints", Paper Presented on the Fourth International Conference on 'Tourism in Southeast Asia \& Indo-China: Development, marketing and Sustainability.

21. Ma, B. and Song, Ma, J. B. D.; and Song, H. (2003), "ICTs and Internet Adoption in China's Tourism Industry", International $J$. of Information Management, 23(6), 451-467. https://doi.org/10.1016/j.ijinfomgt.2003.09.002

22. Mathur, L.K.; I Mathur. I., and Gleason, K.C. (1998), "Services Advertising and Providing Services on the Internet", Journal of Service Marketing, 12(5), 334-347.

23. O'Brien, J. (1992), Management Information Systems: A Managerial End-User Perspective, McGraw-Hill Professional, Pp 670. https://www.amazon.com/Management-Inform ation-Systems-Managerial-Perspective/dp/0256 $\underline{078629}$
24. Rahman MM., and Rahman MS. (2020). Green reporting as a tool of environmental sustainability: some observations in the context of Bangladesh, Int. J. Manag. Account. 2(2), 31-37. https://doi.org/10.34104/ijma.020.031037

25. Raza, I. (2006), Pune postelge-Marketing u turizmu, hotelijerstvu I ugostiteljstvu, Zagreb, M plus. ISBN: 978-953-95111-2-7.

http://library.foi.hr/lib/knjiga.php?sqlx=56026\& sqlid $=20 \& B=20 \& H=$

26. Sardar S, Hossain ME, Hossain MI, and Islam MS. (2020). Factors affecting visitor's satisfaction: an empirical study on the Paharpur Buddha Vihara, Naogaon, Rajshahi, Int. J. Manag. Account. 2(4), 61-73. https://doi.org/10.34104/ijma.020.061073

27. Shili, C. F., (1998), "Conceptualizing Consumer Experiences in Cyberspace", European Journal of Marketing, 32(7/8), 655-663.

28. Slevin, J. (2006). The Internet, Oxford: Blackwell. ISBN (Print): 1405124334.

https://forskning.ruc.dk/en/publications/theinternet

29. Wen-Hsiang L. N. Q. (2013); and Lai, W. and VInh, N. (2013). "How Promotional Activities and Evaluative Factors Affect Destination Loyalty: Evidence from International Tourists of Vietnam", IJMS, 5: 70.

https://doi.org/10.5539/ijms.v5n1p70

30. Young, M. L. et al. (1999), Internet: the Complete Reference, Osborne: McGraw-Hill. Pp 896.

https://www.goodreads.com/book/show/641535 8-internet

Citation: Hossain MA, Suchana JJ, and Avi MAR. (2020). Promoting Bangladesh tourism through the internet: theoretical perspectives and empirical evidence, Can. J. Bus. Inf. Stud., 2(5), 87-95. https://doi.org/10.34104/cjbis.020.087095 (C) () 